Western University Scholarship@Western

Research Program. Impact of the Public Sector on

Research Program. Impact of the Public Sector on

Local Economies Discussion Papers

Local Economies

1977

\title{
Small Cars, Large Cars, and the Price of Gasoline
}

Åke Blomqvist

Walter Haessel

Follow this and additional works at: https://ir.lib.uwo.ca/economicsipsle_dp

Part of the Economics Commons

Citation of this paper:

Blomqvist, Åke, Walter Haessel. "Small Cars, Large Cars, and the Price of Gasoline." Research Program. Impact of the Public Sector on Local Economies Discussion Papers, 017. London, ON: Department of Economics, University of Western Ontario (1977). 


\section{Discussion Paper 017}

SMALL CARS, LARGE CARS, AND THE

PRICE OF GASOLINE

Ake G. Blomqvist ${ }^{\dagger}$

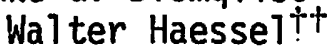

\section{RESEARCH PROGRAM: IMPACT OF THE PUBLIC SECTOR ON LOCAL ECONOMIES}

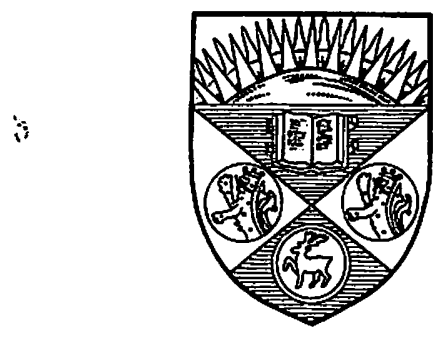

JAN 251977

Upirersity of Westere Ontario

\section{Department of Economics}

The University of Western Ontario

London Ontario Canada 


\section{Discussion Paper 017}

SMALL CARS, LARGE CARS, AND THE PRICE OF GASOLINE

Áke G. Blomqvist ${ }^{\dagger}$

Wa? ter Haessel ${ }^{\dagger+}$

January 1977

\footnotetext{
†university of Western Ontario.

${ }^{+}$Pennsylvania State University.
} 
SMALL CARS, LARGE CARS, AND THE PRICE OF GASOLINE*

\section{Introduction}

From the point of view of the North American automobile industry, one of the most significant events in recent years has been the much discussed shift in the pattern of consumer demand away from the traditional "large" passenger car towards the smaller cars of the compact or sub-compact varieties. The story of the inroads of European and Japanese imports into the North American market, and the subsequent reaction of the domestic industry in the form of introducing their own small models, is well known. Recently, of course, the question of small vs. large cars has assumed increased importance as a consequence of their differential fuel economy and hence impact on energy consumption, and deliberate tax policies aimed at reinforcing the shift in demand towards smaller cars have been introduced in Canada.

While there have been a number of studies of the demand for passenger cars in North America, ${ }^{1}$ as far as we are aware none of them has explicitly

\section{*}

The extremely competent and diligent research assistance of Heather Cohen, Linda Newton and Paul Boothe in the completion of this research is gratefully acknowledged. The research was financially supported by a grant from the General Motors Corporation. An early version of the paper was read at the June 1976 meetings of the Canadian Economics Association, and we received a number of useful comments there.

${ }^{1}$ See, for example, H. Brems, "Long-Run Automobile Demand," Journal of Marketing 20 (April 1956), pp. 379-384; G. 0. Chow, Demand for Automobiles in the United States, Amsterdam: North-Holland, 1957; J. G. Cragg and R. S. Uhler, "The Demand for Automobiles," Canadian Journal of Economics 3, No. 3 (August 1970), pp. 386-406; M. J. Farrel, "The Demand for Motor-Cars in the United States," Journal of the Royal Statistical Society, Series A, Vol. 117 (1954), pp. 171-193; M. Nerlove, "A Note on Long-Run Automobile 
addressed the question of small vs. large cars. The main purpose of this paper is to make a first attempt at disaggregating the demand for passenger cars by size class and to estimate separate demand functions by size and age category. ${ }^{1}$ Indirectly, we are also trying to contribute a partial answer to the question of the effectiveness of various types of policies designed to conserve gasoline, not only by considering the elasticity of demand for different types of cars with respect to car prices, but also by attempting to take into account the differential effect of changing gasoline prices on the demand for cars of different sizes.

Our empirical analysis is based on Canadian data which consist of a cross-section of eight provincial time series for the period 1971-1975. 2 This sample is not ideal: the variation in many of the variables of interest (such as prices of new and used cars, gasoline prices and per capita real

Demand," Journal of Marketing 22 (July 1957), pp. 57-64; and D. B. Suits, "Exploring Alternative Formulations of Automobile Demand," Review of Economics and Statistics 63 (February 1961), pp. 66-69. The pioneering studies of automobile demand were by $P$. de Wolff, "The Demand for Passenger Cars in the United States," Econometrica 51. (Apri1 1938), pp. 113-129; and C. F. Roos and V. von Szelski, "Factors Governing Changes in Domestic Automobile Demand," in General Motors Corporation, The Dynamics of Automobile Demand, New York, 1939. None of these studies, however, was specifically interested in the effect of changes in gasoline prices on automobile demand, and very few included gasoline prices in their analysis.

${ }^{1}$ Cragg and Uhler, op. cit., have discussed the demand for different types of cars in a conceptual framework. However they do not attempt to estimate the demand for different types of cars. Farre11, op. cit., has studied the demand for cars in different age groups. Neither Cragg and Uhler nor Farrell investigate the effect of gasoline prices.

2 Data on new car registrations for Manitoba and Saskatchewan were not available for some years, and we excluded these provinces from the sample. 
income) would be larger, and could probably be more consistently measured, with a single long time series rather than a cross-section of short ones. Secondly, the provincial cross-section introduces a number of effects on the demand for automobiles (such as climate and geography) which are difficult to control for in the estimation and which would not be present in a sample consisting of a longer time series for a given observation unit. On the other hand, short time series avoid certain conceptual difficulties associated with technological change that would be introduced by a longer series. In any event, data limitations forced us to use a cross-section of short time series.

The paper is organized as follows. In section II, we specify a model of the demand for different types of passenger cars and derive the basic form of the estimating equations. Section III contains a brief discussion of data construction. In section IV we describe the results of our empirical estimates, and in section $V$ we report on a set of forecasting and simulation exercises generated on the basis of the estimated model.

\section{The Demand for Passenger Cars}

In this section, we specify the theoretical model underlying our estimating equations. The analysis is carried out in two steps. We first discuss the factors determining the demand for the flows of services from different types of passenger cars within a static equilibrium framework in which we neglect the effects of transactions costs and lags in the adjustment of actual to desired service flows. The equilibrium demand for passenger car services can then be translated into a set of desired stock of cars to be owned by consuming units. Since the costs of adjusting the actual 
stocks of cars to the desired stocks may be quite high, given subjective costs associated with changing cars as well as substantial transactions costs, we then postulate a dynamic model in which adjustment to the desired configuration of car stocks takes place with a time lag. In specifying such a model, we recognize that both for the individual consuming unit and for the market as a whole, the speed of adjustment in the market for a particular type of car is not independent of the actual stocks of other types of cars. We therefore formulate a generalized version of the simple partial adjustment model in which the change in the actual stock of a given type of car depends on the discrepancies between actual and desired stocks for all car types.

Turning first to the static model generating the desired demands, we begin by considering the decision problem of an individual consumer (or consuming unit) who is facing the question whether to own, and hence consume the services of, a particular type of car. We assume that three types of arguments enter his utility function: the quantity of transportation services (number of miles driven, say); the perceived style and comfort in which the occupants of his car are transported; and all other goods and services. The second type of commodity (which we call "ownership services") is of course difficult to quantify; the assumption we make here is that passenger cars can be subdivided into a number of size and age classes, and we hypothesize that cars in bigger and newer classes yield more "ownership services" than smaller and older cars.

Assuming that the consumer maximizes utility subject to a budget constraint, the solution to his decision problem consists of a consumption plan specifying whether or not to own one or more cars, what types of cars to own, how many miles to drive, and what quantity of other goods and 
services to consume. The relevant prices which enter the solution (in addition to his real income) will be the fixed cost of owning each particular type of car per unit of time (consisting roughly of depreciation, interest costs, licence fees, and insurance) and the price of mileage (gasoline, oil, tires, and repairs per mile driven) for each type of car, relative to the price index of other goods and services.

In analyzing the nature of the solution to the consumer's maximization problem, we will specialize the model, first by assuming that each consuming unit (family) will decide to own either one or two cars or no car at all, and second, by distinguishing between only two car age classes ("new" and "old") and two size classes ("large" and "small").

We first note that the probability that a consumer will own at least one car should be negatively related to "rental prices" of all cars, ${ }^{2}$ and also to the prices of mileage; on the assumption that automobile transportation is not an inferior good, it should be positively related to income. Now consider the question of the type of car to own. For those consuming units owning one car only, one would expect that the probability that they would own a car in a given age-size class would be negatively related to the own price but positively related to the prices of cars in all other categories, and similarly for the prices of mileage. With respect to the income variable, one would expect (assuming that "ownership services" are not inferior) that consumers with higher incomes would be more likely to

1 Due to data problems, the system we estimate has only three age-size categories. However, the logical argument is more easily developed using a four-way classification.

2We use the term "rental price" to distinguish the price of car services over a period of time from the price of a car at a point in time. 
hold newer and bigger cars than those with lower income.

Consider now those consumers who decide to own two cars. One would group would depend positively on income and negatively on all car prices and prices of mileage. The probability that a two-car family would hold one car in a particular age-size class is determined in a more complex way. As before, one would expect a negative relation with the own-price of a particular car category. The effect of prices of ownership and mileage in other size-age classes cannot be predicted a priori, however. Consider for example the effect of a fall in the price of new large cars. This might induce two-car families to own bigger or newer cars as second cars, rather than smaller, older cars, so that the demand for "big old" and "new small" cars may be negatively related to the price of "big new" cars for this category of consumers, and similarly for other prices of ownership and mileage. The effect of income changes on the demand for different types of cars also becomes more difficult to predict if there are significant numbers of two-car families.

As we have noted above, the data we use consist of a provincial crosssection of time series. Based on the arguments above, we now postulate that the aggregate desired demand for the stock of cars in age class a and size class $\underline{i}, s_{a i}^{*}$, for a given province and year is determined by:

$$
S_{a i}^{*}=f(R, \pi, Y) \text {, }
$$

${ }^{1}$ For example, if rising income were to induce many people to shift into the two-car category by buying a small car, they might simultaneously decide to hold on to their large cars over a longer period, which would on the average decrease the demand for "new large" cars, even though such cars yield more "ownership services" than other types. 
where $R=\left\{R_{a i}\right\}, I=\left\{\pi_{a i}\right\}$ are vectors of prices of ownership and prices of mileage of cars in the various age, and size classes, respectively, and $Y$ is the level of real income. It follows from the previous discussion that we can hypothesize $\partial S_{a i}^{*} / \partial R_{j k}<0$ when $a=j$ and $i=k$, but the signs of the partial derivatives with respect to other prices of ownership cannot be specified in general. The sign of $\partial S_{a i}^{*} / \partial Y$ cannot be rigorously specified either: while one certainly would expect that the total demand for cars would be positively related to income, rising income may lead to shifts among age-size classes and from the one-car to the two-car category such that for some car classes the relationship may be negative.

For reasons of data availability, we further modify the basic specification (1) in several ways. First, instead of estimating "rental prices" of car ownership, we include the observed retail prices of cars in different age-size classes. 1 Second, we have not been able to collect usable

${ }^{1}$ A rationale for this procedure can be provided as follows. For a new car of given size, the actual cost in the form of interest and amortization of owning it until it gets "old," $R_{n i}$, can be found from the formula:

$$
P_{n i}=\sum_{j=0}^{n_{1}-1} \frac{R_{n i}}{(1+r)^{j}}+\frac{c P_{0 i}}{(1+r)^{n_{1}-1}} \text {, }
$$

or

$$
R_{n i}=\left(P_{n i}-\frac{c P_{0 i}}{(1+r)^{n_{1}-1}}\right) / \sum_{j=0}^{n_{1}-1}(1+r)^{j} \text {, }
$$

where $P_{n i}$ is the purchase price of a new car in size class $i, P_{0 i}$ is the price of a car in size class $i$ which has just become old, $r$ is the relevant rate of interest, $c$ is a constant which reflects pecuriary transactions costs and is the ratio of selling and buying prices of cars which have just become old, and $n_{1}$ is the age at which a car ceases to be a "new" car.

Similarly, for an old car in size class $i$, assuming that it has a zero scrap value and has to be scrapped at age $n_{1}+n_{2}$, one obtains: 
data for the price of mileage by size and age class. To circumvent this problem, we postulate that the relative prices of mileage for different cars remain unchanged across provinces and over time. Formally, we postulate that the vector $\pi$ for a given year and province can be written as $\{\pi\}=\Pi_{m}\left\{c_{a i}\right\}$ where $\Pi_{m}$ is a scalar index of mileage costs for an average car in a given year and province, and the $c_{a i}$ 's are constants reflecting the relative costs of mileage for different types of cars. On the basis of this argument, we replace the vector $\pi$ by the scalar $\pi_{m}$ in the various demand functions. 1

On the basis of the above arguments, the demand equations (1) may now be rewritten as:

$$
S_{a i}^{*}=F\left(P, \pi_{m}, Y\right),
$$

where $P=\left\{P_{a j}\right\}$, and $\pi_{m}$ is our index of mileage costs. Assuming a linear functional form, each equation in the system (2) can be written as:

$$
R_{0 i}=P_{0 i} / \sum_{j=0}^{n_{2}-1}(1+r)^{j}
$$

If one now assumes that the relevant rate of interest remains constant, $R_{n i}$ and $R_{0 i}$ will be linear functions of $P_{n i}$ and $P_{0 i}$, so that equation ( 1 ) can be written with the $P^{\prime}$ 's as arguments rather than the $R^{\prime} S$.

We have two further implicit assumptions in this argument. The first one is that other costs of ownership services, $i . e$. , insurance, licence fees, etc., can be neglected (we assume that they are proportional to the R's). The second one is that all cars of a given age category and size class are perfect substitutes, so that the rental prices within the age category do not vary with age.

If the $\{\pi\}$ vector enters the demand functions linearly, as it does in the equations we estimate, it would be impossible to estimate separate coefficients for the individual elements of $\pi_{m}\left\{c_{a j}\right\}$. 


$$
S_{a i r t}^{*}=\alpha_{a i}^{*}+\sum_{j=1}^{2} \beta_{a i j}^{*} P_{n j r t}+\sum_{j=1}^{2} \gamma_{a i j}^{*} P_{o j r t}+\varepsilon_{a i}^{*} \pi_{m r t}+n_{a i}^{*} Y_{r t},
$$

where $P_{\text {njrt }}$ and $P_{\text {ojrt }}$ represent the prices of "new" and "old" cars in the $j$ 'th size class $(j=1$ corresponds to "small" cars and $j=2$ to "large" cars) in region $r$ at time $t$, the $\alpha^{\prime} s, \beta^{\prime} s, \gamma^{\prime} s, \varepsilon^{\prime} s$, and $\eta^{\prime} s$ are parameters and the remaining symbols have been previously explained.

Since the parameters do not have region or time subscripts, this implies that the same structure is appropriate over both time and space. Finally we can write the equations in (3) as

$$
s_{t}^{*}=x_{t} \Gamma^{*}
$$

where $s_{t}^{*}$ is an $r \times k$ matrix of desired stocks of cars for each of $r$ regions in $k$ size-age categories at time $t, x_{t}$ is an $r \times m$ matrix of observations on the right-hand side (RHS) variables at time $t$, and $\Gamma^{*}$ is an $m \times k$ matrix of parameters. The index $k$ can take a maximum value of 4 and $m$ a maximum value of 7. When age-size classes are combined, the values of $m$ and $k$ are appropriately reduced.

As we noted above, the actual stocks $S_{t}$ may adjust to the desired stocks $s_{t}^{*}$ with considerable time lags if a discrepancy exists between the two. There are several reasons for this. First, there may be a lag because of habit persistence or non-monetary adjustment costs: the trouble of learning the idiosyncrasies of a different car, changing the insurance coverage, etc. These are time lags which might exist even if cars were customarily rented in a short term rather than owned. In addition, however, when most cars are owned, there are significant monetary adjustment costs. For all these reasons, one would expect only a gradual response of actual to desired stocks, so that a specification involving some form of partial 
adjustment mechanism suggests itself. We specify a generalized version of the one-variable partial adjustment mechanism in which the rate of change of the actual stock of cars in a particular age-size class is related to the discrepancy between desired and lagged actual stocks in all age-size classes. This gives rise to the system

$$
\Delta S_{t}=\left(x_{t} \Gamma^{*}-S_{t-1}\right) \lambda+e_{t}
$$

where $\Delta S_{t}$ is an $r \times k$ matrix of observed changes in the regional car stocks in the different age-size classes, $e$ is an $r \times k$ matrix of error terms, and $\lambda$ is a $k \times k$ matrix of adjustment speeds, with $\lambda_{i j}$ corresponding to the impact of a discrepancy between desired and lagged actual stocks of cars in the $i$ 'th class on the rate of change of actual stocks of cars in the $j^{\prime}$ th class, and $S, X$ and $\Gamma^{*}$ are as defined above. In the special case where $\lambda$ is a diagonal matrix, (5) corresponds to $\mathrm{k}$ simple adjustment models in which the speed of adjustment for each stock depends only on the discrepancy between the desired and lagged stock in the given age-size class itself. We do not in general expect the off-diagonal elements of $\lambda$ to be zero, however.

The system (5) can also be rewritten as:

$$
s_{t}=x_{t} \Gamma+s_{t-1}(I-\lambda)+e_{t}
$$

where $\Gamma=\Gamma^{*} \lambda$ and $I$ is a $k \times k$ identity matrix, and this was the basic form in which the model was empirically estimated.

Our division of the stock of cars into size classes was based on the standard industry classification of cars into subcompact, compact, intermediate, and standard cars. After some experimentation with three size classes and alternative groupings of two size classes, we finally settled on subcompacts as "small" cars and aggregated compact, intermediate 
and standard cars into the "large car" category.

The division of the total stock of cars into age categories was done by designating cars up to and including three years old as "new," and all others as "old."1 The restriction of the analysis to two age categories, and the dividing line between new and old was primarily dictated by data considerations. We did not have price data for cars older than four years, and we could only construct data by size class for stocks of cars older than four years using an indirect method involving a number of arbitrary assumptions. Partly because of the latter problem, we further aggregated the model by combining large and small old cars into a single "old car". class. We believe the estimates from this version to be the most reliable ones, and they are the ones reported in the present paper. 2

In estimating the equations, we considered the prices of new cars as given by the manufacturers (and hence exogenous) and the stock of new cars in each size class as endogenous. Since the Canadian provinces form a relatively small part of the North American market, the assumption implied by this, i.e., that purchases of new cars in a given year will not significantly affect the price during that year, seems a reasonable one. The stocks of old cars in a given year and province, however, are treated as

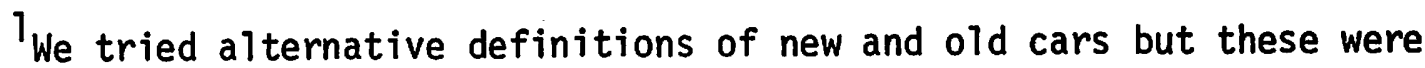
found to be less satisfactory.

2In an alternative version, we did attempt to divide the old car category into large and small cars. However, multicollinearity problems for this case forced us to aggregate new and old small cars into a single small-car category, so that this specification also contains three age-size classes. Results for this version of the model are available upon request from the authors. 
exogenous $^{1}$ and the corresponding prices are endogenous. Consequently, the equation for old cars was estimated with price as the dependent variable. Income and the price of mileage are considered exogenous to the system, and the lagged values of the stocks of new and used cars are predetermined in any given year. Given these assumptions, each equation is exactly identified since the number of exogenous variables in the system which are excluded from each equation is just one less than the number of endogenous variables included.

\section{The Data}

Our sample roughly spans the time period 1971-1975. The data on stocks of "new" cars by size class are derived from provincial new car registration data by model type for calendar years. The price data refer to model years. An attempt was made to reconcile the differences between model year sales and calendar year new-car registrations by computing the quantity of new cars sold of size class $i$ for model year $t$ in region $r, R_{i r t}$, as one-third of the calendar-year registrations in year $(t-1)$ plus two-thirds of calendar-year registrations in $t$. (Our data are based on car sales up to and including 1975 model cars.) The stock of new cars in year $t$ is then computed as

$$
S_{n i r t}=\sum_{j=0}^{2} \Psi_{j} R S_{i r, t-j},
$$

If interprovincial trade in used cars were a significant phenomenon, this treatment would not be appropriate and the stocks of old cars would then have to be treated as endogenous as we1l. This would also require specification of the determinants of interprovincial trade. We are not aware of any data on interprovincial trade in used cars and have neglected the problem in the hope that it is not quantitatively important. 
where $\psi_{j}$ is the "death rate" of j-year old cars. "Thus, $S_{\text {nirt }}$ is. the stock of cars from zero to three years $01 d^{2}$ in size class $i$, region $r$, at time $t$. As noted above, we did not distinguish between size classes for "old" cars. The total stock of "old" cars was simply computed as:

$$
S_{\text {ort }}=S T_{r t}-S_{n s r t}-S_{n e r t} \text {, }
$$

where $\mathrm{ST}_{r t}$ is the total stock of passenger cars registered by province for the corresponding registration year, ${ }^{3}$ and $S_{n s r t}$ and $S_{n \ell r t}$ denote new smal1 and new large cars respectively. Estimated stocks were divided by provincial population to obtain values per 1,000 inhabitants.

New and used car prices are derived from the Canadian Red Book. New car prices are manufacturer's suggested retail price obtained from the 1975 Reference Edition of the Red Book, and used car prices for comparable cars three years old come from various monthly editions. Prices were originally computed for three size classes (subcompact, compact, and large) and for each category and model year was a quantity weighted average, based on Ontario sales and price data, of the three largest selling imported or domestically

${ }^{1}$ Data on new car registrations by province were obtained from R. L. Polk Ltd., Toronto. We derived values of $\psi$ from a table of estimated mortality rates for passenger cars pertaining to the U.S., which was made available to us by General Motors of Canada. It is possible that death rates for cars in Canada are different from those in the U.S., and they may also differ by province. Furthermore, they may differ between large and small cars. Unfortunately, we have no way of taking these factors into account, but their influence is certain to be minor as long as attention is confined to cars less than four years old.

${ }^{2} \mathrm{~A}$ car becomes an old car at the beginning of its fourth year, i.e., after it has reached its third birthday.

${ }^{3}$ Total cars registered by province are available in Statistics Canada publications. 
manufactured model types for that particular model year. Prices for other provinces were then computed using adjustment factors given in the Red Book; it is worth noting that these factors were revised only once during the 1971-1975 period. When the compact and large classes were aggregated into a single "large" category, the price of large cars was a similar quantityweighted average of the initial two categories for each province. We used the price of large old cars as an index of all old car prices, since by far the largest proportion of old cars are in the large category.

The price of gasoline, which was used as our proxy for $\pi_{m}$, is based on regional city price indices which are adjusted for regional differentials.' The income variable used is GNP by province, 1970-74, divided by population; these series were obtained directly from Statistics Canada. A11 prices and incomes are deflated by a national consumer price index. Ideally, the consumer price index should be adjusted using a comprehensive index of regional cost of living differentials. Unfortunately such an index does not appear to be available for Canada at this time.

Before turning to the empirical results, it might be of interest to note some of the main patterns in the data. First, the trend towards small cars is very much in evidence during the early part of the period, with very large increases in the stock of new small cars, in all provinces, in 1971-1973.

Te obtained gasoline price indices, directly from Statistics Canada, by regional city for the period 1973-75, on a monthly basis, with $1973=100$. These were adjusted by the gasoline component in the regional cost-of-living differentials table in Statistics Canada, Prices and Price Indexes (monthiy), Table 14, February 1975. Regional indices were not available for the years prior to 1973 so we used the national gasoline price series and linked it to the later series for each city. The price indices were computed as simple averages of October and April figures to correspond to model year car sales. 
In 1974, however, the stocks seem to have stabilized and in 1975 there was actually a significant decrease in the stock of new small cars in all provinces. With respect to new large cars, the stocks remained essentially stable or actually decreased in 1971-72, but in 1974 and 1975 there were big increases. There have been major changes in the relative prices of large and small new cars: in all provinces, the real price of new large cars in 1975 was significantly lower than in 1971, with the big decrease coming in 1974, whereas our index for new small-car prices has risen substantially over the period, with a big increase again in 1974. The real price of gasoline did not generally rise over the period: in all but one province, it was actually lower in 1975 than in 1971, in some cases substantially so. 1 Therefore, the period during which the trend toward small cars was most in evidence (1971-73) was one of a falling price of gasoline in real terms.

\section{Empirical Results}

In this section we present estimates of the demand equations for new small and large cars and an equation for old cars. First, however, we discuss the estimation method used.

Recently there has been a good deal of discussion of the estimation of models from time series of cross-sections. For example, Nerlove has extensively studied a variety of models involving a lagged dependent variable using Monte Carlo techniques. ${ }^{2}$ Maddala has studied the same case analytically

${ }^{1}$ Since our 1975 gasoline price index is a simple average of October 1974 and Apri 1975 figures, our data do not reflect the substantial increase in gasoline prices toward the end of 1975 .

${ }^{2}$ See M. Nerlove, "Further Evidence on the Estimation of Dynamic Economic Relations from a Time Series of Cross Sections," Econometrica 39 (March 1971), pp. 359-382 and the numerous references cited there. 
as well as the estimation of systems of simultaneous equations from pooled cross-section and time series data. 1 The Nerlove and Maddala results for models involving only lagged dependent and ex̃ogenous RHS variables are relevant to the estimation of our reduced forms. However, we are unaware of any discussion of the estimation of models involving lagged dependent, exogenous and endogenous RHS variables with pooled cross-section and time series data, and we decided simply to estimate our structural equations using both ordinary least squares (OLS) and two-stage least squares (TSLS), and we present both sets of results.

In some cases, the coefficients estimated by OLS differed substantially from those in the TSLS equations. We are somewhat uncertain how to interpret these differences. Since the new car equation always contain one endogenous RHS variable, OLS will be biased and inconsistent. ${ }^{2}$ Some recent work on the small sample properties of TSLS suggests that in many cases the exact moments do not exist, especially in cases where the degree of overidentification of the equation is small (such as in our model). ${ }^{3}$ our estimation

${ }^{1}$ See G. S. Maddala, "The Use of Variance Components Models in Pooling Cross-Section and Time Series Data," Econometrica 39 (March 1971), pp. 341-358.

${ }^{2}$ The introduction of a lagged dependent variable on the RHS will be sufficient to bias the OLS estimates, whether or not the models were estimated from pooled cross-section and time series data. TSLS estimates are always biased in small samples (if the moments exist). The introduction of a lagged dependent variable probably introduces a further bias but TSLS should still be consistent.

${ }^{3}$ See R. Mariano, "The Existence of Moments of the OLS and TSLS Estimators," Econometrica 40. (July 1972), pp. 643-652, and R. A. L. Carter, "The Exact Distribution of an Instrumental Variables Estimator," International Economic Review, forthcoming. The Mariano and Carter results were derived without the added complications of lagged endogenous variables and pooled cross-section and time series data. We are indebted to Robin Carter and Aman Ullah for discussions of these points. 
problem was further exacerbated by a high degree of multicollinearity between some of our price variables.

When all of these estimation problems are combined, the statistical properties of our structural estimates are somewhat uncertain and further exploration of this area would be fruitful. We will, however, attempt to indicate some of the biases that may exist, based on analogies with the Nerlove and Maddala models.

We turn now to a discussion of the empirical results. Table 1 presents OLS and TSLS estimates for the new car equations, and an estimate of the demand function for old cars (using price as the dependent variable in the latter case). In some respects, the results are disappointing: many of the coefficients are small relative to their standard errors, and some of the coefficients of the lagged stocks appear implausible. ${ }^{1}$ Nevertheless, bearing in mind the nature of the sample and the somewhat arbitrary nature of the age/size disaggregations, the percentage of the variance explained by this simple formulation is quite high, especially for the new car equations, and most of the signs are consistent with one's a priori expectations.

The short-run elasticities of the demand for stocks of different types of cars with respect to prices and income are presented in Table $2 .^{2}$ The elasticities with respect to car prices do not contain any major

\footnotetext{
${ }^{1}$ These latter coefficients are likely to be severely biased as we discuss below.

${ }^{2}$ If the Nerlove, op. cit. and Maddala, op. cit., results could be shown to be applicable to our mode1, they would imply that the estimated elasticities for the new-car equations are biased toward zero. Since the RHS of the old-car equation contains neither endogenous variables nor the lagged value of the dependent variable, the regression coefficients for that equation should be unbiased.
} 
TABLE 1. Mode] I, Estimates*

New Car Equations

\begin{tabular}{|c|c|c|c|c|c|c|c|c|c|c|}
\hline $\begin{array}{l}\text { Dependent } \\
\text { Variable }\end{array}$ & Const. & $P_{n s}$ & $P_{n \ell}$ & $P_{0}$ & $Y$ & $\pi_{m}$ & $S_{n s, t-1}$ & $S_{n \ell, t-1}$ & $S_{0, t-1}$ & $R^{2}$ \\
\hline $\begin{array}{l}\text { New small cars } \\
(\text { OLS })\end{array}$ & $\begin{array}{c}6.4 \\
(16.4)\end{array}$ & $\begin{array}{r}-2.04 \\
(.37)\end{array}$ & $i_{(.36)}^{907}$ & $\begin{array}{l}510 \\
(.37)\end{array}$ & $\begin{array}{l}1.98 \\
(1.69)\end{array}$ & $\begin{array}{l}699 \\
(6.1)\end{array}$ & $\begin{array}{l}1.03 \\
(.075)\end{array}$ & $\begin{array}{l}-.054 \\
(.038)\end{array}$ & $\begin{array}{l}-.004 \\
(.010)\end{array}$ & .9788 \\
\hline $\begin{array}{l}\text { New large cars } \\
(\text { OLS })\end{array}$ & $\begin{array}{c}38.3 \\
(27.8)\end{array}$ & 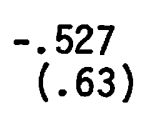 & $\begin{array}{r}-1.84 \\
(.61)\end{array}$ & $\begin{array}{l}3.70 \\
(.63)\end{array}$ & $\begin{array}{c}1.09 \\
(2.86)\end{array}$ & $\begin{array}{l}-13.1 \\
(10.4)\end{array}$ & $\begin{array}{l}.017 \\
(.121)\end{array}$ & $\begin{array}{l}.939 \\
(.066)\end{array}$ & $\begin{array}{l}-.044 \\
(.017)\end{array}$ & .9773 \\
\hline $\begin{array}{l}\text { New sma } 11 \text { cars } \\
\text { (TSLS) }\end{array}$ & $\begin{array}{c}2.65 \\
(18.7)\end{array}$ & $\begin{array}{r}-2.79 \\
(.78)\end{array}$ & $\begin{array}{l}.874 \\
(.402)\end{array}$ & $\begin{array}{l}1.56 \\
(.999)\end{array}$ & $\begin{array}{c}1.31 \\
(1.98)\end{array}$ & $\begin{array}{l}5.38 \\
(7.99)\end{array}$ & $\begin{array}{l}1.03 \\
(.080)\end{array}$ & $\begin{array}{l}-.039 \\
(.045)\end{array}$ & $\begin{array}{l}-.004 \\
(0.13)\end{array}$ & \\
\hline $\begin{array}{l}\text { New large cars } \\
\text { (TSLS) }\end{array}$ & $\begin{array}{c}39.8 \\
(28.4)\end{array}$ & $\begin{array}{l}-.229 \\
(1.18)\end{array}$ & $\begin{array}{l}-1.83 \\
(.612)\end{array}$ & $\begin{array}{l}3.29 \\
(1.52)\end{array}$ & $\begin{array}{r}1.36 \\
(3.01\end{array}$ & $\begin{array}{l}-15.0 \\
(12.1)\end{array}$ & $\begin{array}{l}.019 \\
(.122)\end{array}$ & $\begin{array}{l}.933 \\
(.069)\end{array}$ & $\begin{array}{l}-.047 \\
(.020)\end{array}$ & \\
\hline
\end{tabular}

01d Car Equations (OLS)

\begin{tabular}{|c|c|c|c|c|c|c|c|c|c|c|}
\hline & Const. & $P_{n s}$ & $P_{n \ell}$ & $s_{0, t}$ & $Y$ & $\pi_{m}$ & $S_{n s, t-1}$ & $s_{n \ell, t-1}$ & $S_{0, t-1}$ & $\mathrm{R}^{2}$ \\
\hline Price of 01d Cars & $\begin{array}{l}9.28 \\
(7.6)\end{array}$ & $\begin{array}{l}.715 \\
(.114)\end{array}$ & $\begin{array}{l}-.105 \\
(.167)\end{array}$ & $\begin{array}{l}-.0224 \\
(.0088)\end{array}$ & $\begin{array}{l}1.25 \\
(.78)\end{array}$ & $\begin{array}{l}-5.63 \\
(2.64)\end{array}$ & $\begin{array}{c}-.015 \\
(.032)\end{array}$ & $\begin{array}{l}-.027 \\
(.0177)\end{array}$ & $\begin{array}{l}.0135 \\
(.0095)\end{array}$ & .796 \\
\hline
\end{tabular}

* The numbers in parentheses are estimated standard errors. The total number of observations was 40 . 
TABLE 2. Model I, Elasticities

\begin{tabular}{lrrrrr}
\hline & $P_{n s}$ & $P_{n \ell}$ & $P_{0 \ell}$ & $Y$ & $\Pi_{m}$ \\
\hline 0LS: & & & & & \\
New smal1 cars & -1.19 & .91 & .20 & .13 & .02 \\
New large cars & .12 & -.73 & .66 & .03 & -.13 \\
01d cars & 2.72 & -.68 & -2.92 & .56 & -.95 \\
TSLS: & & & & & \\
New smal1 cars & -1.63 & .87 & .70 & .09 & .14 \\
New large cars & -.05 & -.73 & .59 & .04 & -.15 \\
& & & & & \\
\hline
\end{tabular}


surprises: for the new car equations, the own-price elasticity is negative, significant, and fairly large, with the own-price elasticity of demand for small cars estimated to be in excess of unity. Also for new cars, the cross-price elasticities mostly indicate gross substitutability between different types of cars: as one might expect, there is a fairly high elasticity of demand for new large cars with respect to the price of old cars.

Concerning the cross-effects of new car prices, there is an interesting asymmetry: an increase in the price of new large cars tends to cause a fairly substantial shift in demand towards new small cars, but not into old cars. An increase in the price of new small cars, on the other hand, shifts demand mainly toward old cars, but not toward new large cars. This pattern is consistent with the idea that at any given time there is a subgroup of consumers who primarily buy either small or old cars (perhaps young people or low-income families in general) but will not consider a large new car; for those who may be willing to buy a large new car, however, the choice between a large or a small new car depends primarily on the price of large new cars. The two groups are linked through the market for old cars, however, since the elasticity of either type of new car with respect to the price of old cars is fairly substantial, at least in the TSLS equations. The cross-elasticities with respect to the new small car price may also to some extent reflect the two-car phenomenon: an increase in this price may cause two-car families owning a large car to delay replacing it, which would raise the demand for old cars but reduce or leave unchanged that for new large cars, which is consistent with the pattern in Table 2.

The income elasticities are implausibly small. Apart from the fact 
that our data on the income variable are somewhat shaky, ${ }^{1}$ we suspect that another reason for this is that it is highly correlated with the lagged car stocks; this might also in part explain the somewhat erratic pattern in the signs and magnitudes of the coefficients for the lagged car stocks.

The elasticities of demand for new large cars with respect to the price of gasoline has the expected sign and, as one would expect a priori, is less in algebraic value than that for new small cars; it is interesting to note that the latter elasticity is positive and almost as large in absolute value as that for large cars in the TSLS equation. In all the new car equations, however, the short-run elasticities are relatively small and derived from coefficients that are at best only slightly larger than their standard errors. Hence, we must conclude that the present evidence indicates at most a fairly modest short-run shift in new car demand in favour of small cars in response to a change of gasoline prices. ${ }^{2}$ When we consider the demand for old cars, however, we observe an estimated elasticity of about -1 which is much larger in absolute value than those for the new cars; it is also based on a coefficient in the old car equation which is more than twice as large as its standard error. We believe that this effect is due partly to the fact that the largest portion of old cars in the present data are large cars, and partly to the fairly high degree of substitutability between new small and old cars. This suggests a relatively strong indirect channel through which an increase in the price of gasoline

${ }^{1}$ The income variable is provincial GNP per capita on a calendar-year basis. Thus the 1974 calendar-year income corresponds to 1975 model-year car sales (which begin in 1974) introducing a lag of approximately 8 months. Some concept of permanent income would probably be more desirable.

${ }^{2}$ Once again, however, the Nerlove-Maddala results, if applicable to this model, indicate that these coefficient estimates are biased toward zero. 
will affect the new car markets. Because the stock of old cars at a point in time is largely exogenous, a shift in the demand due to such a change will affect the price of old cars; but since the cross-price elasticity of demand for new cars, large and small, with respect to the price of old cars, is positive and relatively substantial, this will lead to a downward shift in the demand for new cars.

We finally consider the question of estimation of the long run demand functions, as described by (4) above. An inspection of the coefficients of the lagged stocks in Table 1 indicates that the estimated speeds of adjustment (the elements of the matrix $\lambda$ in (5) above) through the markets for new cars are extremely low, and some of the coefficients have unexpected signs. The estimated coefficients of the lagged stocks, however, are likely to be severely biased toward unity. 1 Since solving for the long-run demand equations will involve the inverse of the $\lambda$ matrix, any bias in the estimated coefficients on the lagged stocks would be exacerbated. Hence, we conclude that the specified model cannot be usefully employed to estimate long-run

${ }^{1}$ Maddala op. cit., indicated that the OLS estimates of the lagged dependent variable wili be biased towards one if only lagged dependent and exogenous variables are included on the right-hand side of the equation. Nerlove's Monte Carlo studies op. cit., have indicated that this bias will be very severe if a substantial proportion of the residual variance (var (e) in our equation (5)) is the result of variation between provinces. We expect this to be the case.

One method of controlling for this variation between provinces is to include separate dummy variables for each province. Both Maddala and Nerlove have indicated this will result in estimated coefficients for the lagged stocks which are severely biased towards zero. Maddala has also indicated that using dummy variables to capture individual effects is an inefficient method. We did experiment with the inclusion of provincial dummies and found that many of our slope coefficients, as well as many of the provincial dummies were statistically insignificant and the resulting point estimates were somewhat erratic. Consequently, these estimates are not reported. 
demand functions with the estimating techniques and data currently available. However, if the Maddala-Nerlove results can be applied to our model, the estimated short-run elasticities reported in Table 2 can be considered lower bound estimates to the absolute values of these parameters.'

\section{New Car Sales and the Price of Gasoline}

In this section, we turn to a discussion of forecasting new car sales with special reference to the impact of a change in the price of gasoline. Since the above model is a simultaneous model with three endogenous variables (the stocks of small and large new cars and the price of old cars), we estimated the reduced forms of the new car equations to use in forecasting. The OLS estimates are presented in Table 3 and the corresponding elasticities of the demand for new cars with respect to prices and income are shown in Table $4 .^{2}$ Certain aspects of these results are of considerable interest. First, the cross-elasticities with respect to new car prices are now positive and relatively large in both equations. Second, once the indirect effects through the used car market are taken into account, the short-run elasticity of demand for new large cars with respect to the price of gasoline is much larger in absolute value than in the structural equations, and the demand for small cars is shown as being essentially unaffected by

${ }^{1}$ This follows from the Maddala-Nerlove conclusion that the coefficients of the exogenous variables will be biased towards zero.

${ }^{2}$ The Maddala-Nerlove results are directly applicable to the reducedform equations for new cars, with the conclusions that the coefficients of the lagged dependent variable is biased towards one whereas all other slope coefficients are biased toward zero. As mentioned above, the estimated demand equation for old cars with price as the dependent variable (Table 1) should be unbiased. 
TABLE 3. New Car Reduced-Form Equations *

\begin{tabular}{|c|c|c|c|c|c|c|c|c|c|c|}
\hline $\begin{array}{l}\text { Dependent } \\
\text { Variable }\end{array}$ & Const. & $P_{n s}$ & $P_{n \ell}$ & $Y$ & $\Pi_{m}$ & $S_{n s, t-1}$ & $S_{n l, t-1}$ & $S_{0, t-1}$ & $S_{0, t}$ & $\mathrm{R}^{2}$ \\
\hline New small cars & $\begin{array}{c}17.1 \\
(16.8)\end{array}$ & $\begin{array}{l}-1.68 \\
(.254)\end{array}$ & $\begin{array}{c}.710 \\
(3.71)\end{array}$ & $\begin{array}{c}3.26 \\
(1.72)\end{array}$ & $\begin{array}{l}-3.37 \\
(5.88)\end{array}$ & $\begin{array}{c}1.00 \\
(.072)\end{array}$ & $\begin{array}{l}-.082 \\
(.039)\end{array}$ & $\begin{array}{l}.0248 \\
(.0208)\end{array}$ & $\begin{array}{l}-.0349 \\
(.0196)\end{array}$ & .9796 \\
\hline New large cars & $\begin{array}{c}70.3 \\
(40.7)\end{array}$ & $\begin{array}{l}2.12 \\
(.615)\end{array}$ & $\begin{array}{l}-2.17 \\
(.899)\end{array}$ & $\begin{array}{c}5.48 \\
(4.18)\end{array}$ & $\begin{array}{l}-33.5 \\
(14.2)\end{array}$ & $\begin{array}{c}-.0309 \\
(.175)\end{array}$ & $(.842)$ & $\begin{array}{l}-.0029 \\
(.0504)\end{array}$ & $\begin{array}{c}-.0737 \\
(.0475)\end{array}$ & .9553 \\
\hline
\end{tabular}

* Numbers in parentheses are estimated standard errors.

TABLE 4. New Car Reduced-Form Elasticities

\begin{tabular}{crrrr}
\hline & $P_{n s}$ & $P_{n \ell}$ & $Y$ & $\Pi_{m}$ \\
\hline New sma11 cars & -1.05 & .71 & .21 & -.088 \\
New large cars & .523 & -.864 & .74 & -.344 \\
\hline
\end{tabular}


the gas price.

These results refer to stocks of new cars, i.e., cars less than four years old. Since adjustments in those stocks take place through purchases of newly produced cars, one may also use them to assess the impact of changes in the exogenous variables on new car sales. Since annual sales are much smaller than the stocks of new cars as defined here, the impact elasticities of sales with respect to the exogenous variables of interest will of course be larger than those shown in Table 4; estimates of the sales elasticities at the means can be found by multiplying those in Table 4 by the ratio of the mean stocks of new cars to mean sales of cars in the corresponding size categories (2.79 for small cars, 2.82 for large). Thus, our results indicate that new car sales in each size category are highly elastic with respect to own prices $(-2.9$ and -2.4 for small and large cars respectively) as well as with respect to prices in the other category $(2.0$ and 1.5 respectively). Referring to the impact of the price of gasoline, the estimates imply that sales of new small cars has an elasticity with respect to that price of about -.25 at the means; sales of large new cars, however, are four times as responsive to the price of gas $(-1.0)$. Thus, our results indicate that the impact on car sales of the recent and projected increases in fuel prices is likely to be quite substantial, both with respect to total passenger car sales and with respect to the composition of sales by size category of car.

The elasticity estimates just discussed, in our view, represent the principal result of the empirical work undertaken in this paper. For reasons which we have given above, we feel that less significance should be attached to the other parameters we have estimated, such as income elasticities and the speeds of adjustment to long-run equilibrium. In order 
to construct an accurate sales forecasting model disaggregated by province and size category of car, the most appropriate procedure would probably be to combine the results of the present model with estimates of the latter parameters from other work based on time series data rather than mixed time series and cross-section data such as we have used here. Despite these misgivings regarding our model, we have, for purely illustrative purposes, used it to construct a set of three hypothetical forecasts of new car sales for the 1976-78 model years under different assumptions regarding the values of some exogenous variables. While the results should not be taken too seriously, we present them to illustrate the orders of magnitude of the response of car sales to changes in those variables.

In all three projections, we assumed that real per capita income would grow by $5 \%$ in 1975 and 1976, and by $3 \%$ per annum thereafter. For simplicity, we assumed constant population during the projection period. For the 1976 model year, we assumed that the real price of gasoline was 15\% higher than for the 1975 model year, and that real new car prices were the same in both years.

In our first projection, we assumed unchanged real prices of gas and new cars during the 1977 and 1978 model years. The results are shown in part I of Table 5. The model generates a fairly constant level of total car sales in the eight Canadian provinces included in the sample. Primarily as a result of the assumed increase in the price of gasoline in 1975/76, sales of 1976 model cars are predicted to shift substantially in favour of small cars, but for 1977 and 1978 models, an increase in large car sales and a decrease for small ones is indicated.

Consider now Alternative II where we assumed a further increase of $25 \%$ in the real price of gas starting in 1977 . As a consequence, the mode 1 
TABLE 5. Model Year Sales Projections (thousands) for Eight Provinces

\begin{tabular}{|c|c|c|c|c|c|}
\hline 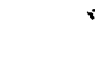 & & 1975 & 1976 & 1977 & 1978 \\
\hline \multirow[t]{3}{*}{ I. } & Smal1 & 188 & 221 & 197 & 169 \\
\hline & Large & 659 & 630 & 662 & 677 \\
\hline & Total & 847 & 850 & 858 & 846 \\
\hline \multirow[t]{3}{*}{ II. } & Small & 188 & 221 & 181 & 167 \\
\hline & Large & 659 & 630 & 516 & 554 \\
\hline & Total & 847 & 850 & 698 & 721 \\
\hline \multirow[t]{3}{*}{ III. } & Small & 188 & 221 & 276 & 270 \\
\hline & Large & 659 & 630 & 417 & 469 \\
\hline & Total & 847 & 850 & 694 & 738 \\
\hline
\end{tabular}

I. Real gasoline and new car prices assumed unchanged in 1977 and 1978.

II. Real gasoline price increased 25\% in 1977 and new car prices assumed unchanged in 1977 and 1978.

III. Real gasoline prices unchanged in 1977 and 1978 but price of large cars increased 20\% in 1977. 
predicts a decline in total sales of approximately 150 thousand cars between the 1976 and 1977 model years, with most of the decrease (114 thousand) coming in the sales of large cars. Sales of large cars are shown as increasing somewhat for the 1978 models, but remain well below the level in the initial prediction.

In Alternative III, we assumed that the price of new large cars would be increased by $20 \%$ in real terms starting with the 1977 models, with small car prices remaining unchanged. The figures for total car sales for 1977 and 1978 are approximately the same as those predicted with the $25 \%$ gas price increase in 1977, but the composition changes drastically: large car sales are shown as decreasing by 213 thousand units in 1977 whereas smal1 car sales increase by 55 thousand (compared to a 40 thousand decrease with the gas price change). ${ }^{1}$

We finally comment briefly on the possible implications of these results for the question of policies designed to reduce the consumption of gasoline used in passenger cars. First, suppose that all vehicles are driven the same number of miles per annum (say, 10,000), and that the gas consumption rates of 1 arge and small cars correspond to 15 and 25 miles per gallon, respectively. Compared to consumption as it would be if sales were given by the initial projection, consumption under the $25 \%$ gas price increase would be 103 million gallons less in 1977 , and 188 million gallons less in 1978. Under the alternative with a $20 \%$ increase in the prices of

$1_{\text {We also generated a similar set of three forecasts on the assumption }}$ that the long-run income elasticity of demand for both small and large cars was 1.5 , and that $50 \%$ of the adjustment to long-run equilibrium would take place within one year. The 1976 forecast under these assumptions indicates much higher total sales, but the reactions to the assumed change in the price of gasoline or new large car prices in 1977 are quite similar to those shown here. 
large cars, the corresponding reductions would be 131 and 231 million gallons respectively. Thus, on the assumption of unchanged mileage, those two policies would yield gasoline savings of roughly the same order of magnitude. If one relaxes this assumption, however, one must also take into account that a change in the price of gas would have a direct impact on the cost of driving a mile, so that such a change would probably have a significant impact on the number of miles driven per car whereas a change in the price of new cars would not. Moreover, this effect would pertain to all cars, not just those sold in the preceding three years. Hence, there would be an additional reduction of gas consumption from this source which we suspect, could well be much larger than that due to the change in the composition of cars. 1

Conclusions

The principal purpose of this paper has been to formulate and estimate a model of the market for passenger cars in Canada in such a way as to throw some light on the determination of the composition of new car demand by size class, as well as on the total demand for new cars. In particular, interest is focussed on the role of actual and projected changes in the

If one takes the total number of cars in Canada to be about 8 million and assumes an average mileage of 8,000 miles per annum at 20 miles per gallon, and an elasticity of miles driven with respect to the price of gas as low as -.1 , a 25\% increase in the price of gas implies a reduction in consumption by about 800 million gallons. Apart from the fact that economic theory strongly suggests that an increase in the price of gasoline is the "efficient" policy if the objective is to reduce gasoline consumption, these numbers seem to indicate what an indirect policy of achieving this objective through increased prices of large cars would have to be of fairly drastic proportions in order to yield results equivalent to a gradual increase in the price of gas. 
price of gasoline in bringing about a relative shift toward smaller, more energy-efficient cars which will contribute toward a reduction in the growth rate of gasoline consumption.

To this end, we have specified a three-equation model which distinguishes between the demand for the services of small and large new cars, defined as cars less than four years old, and older cars. We found that, in general, the demand for each type of car had a relatively high short-term elasticity with respect to its own price, and in some cases also fairly high cross-elasticities with respect to the price of other types of cars. The partial elasticity of demand for new cars with respect to the price of gasoline was found to be relatively small; however, the demand for older cars was found to have a substantial elasticity with respect to the price of gas, and this, coupled with the high cross-price elasticity of new car demand with respect to the price of older cars, indicates a substantial indirect effect on the demand for new cars of changes in the gas price, most of it affecting large new cars.

Because we believe that adjustments in the configuration of stocks of cars in response to changing circumstances take place with a time lag, the model was specified in partial adjustment form. Strong evidence was found that such time lags are present, even though, because of the nature of our data and estimation techniques, we do not believe that we have accurately estimated the parameters representing the speed of adjustment. Hence we conclude that in order to estimate a more complete dynamic model of the market to passenger cars, our work would have to be supplemented in some way by information based on more extensive and reliable time series data, or await the development of more refined estimating techniques. We finally used the results of the model for purposes of illustrating 
the effect on new car sales of hypothetical policies designed to shift passenger car demand in the direction of more energy-efficient smaller cars. Comparing the effects of an assumed $25 \%$ increase in the price of gasoline and a $20 \%$ increase in the price of new large cars in mid-1976, we found that the resulting savings in gas consumption as a consequence of the reduced level of new car demand and the shift in composition toward smaller cars, would be roughly comparable in magnitude. This conclusion was based on an assumption of an unchanged annual mileage per vehicle. However, if one takes into account that a gas price increase would tend to reduce the number of miles driven, and that this effect would affect all cars rather than just new ones, it seems likely that the savings in gasoline consumption would be several times larger with the gas price increase than with the alternative policy of relative price increases for large cars. 
RESEARCH PROGRAM:

IMPACT OF THE PUBLIC

SECTOR ON LOCAL ECONOMIES

The Department of Economics, University of Western Ontario, has recently mounted a long-term research program on the Impact of the Public Sector on Local Economies. The program publishes Discussion Papers and Research Studies. Copies may be obtained by writing:

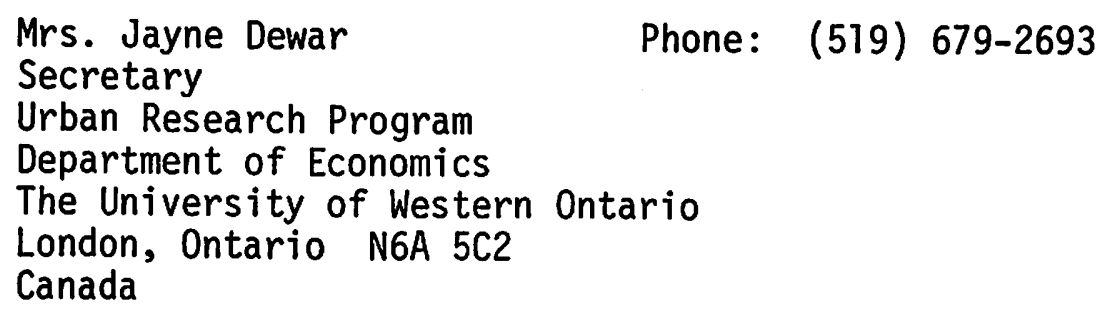

The following Discussion Papers and Research Studies are currently available:

\section{DISCUSSION PAPERS:}

* 001 P.T. Chinloy, "Hedonic Prices and Age Deterioration in Urban and Suburban Housing" (September 1975). [30 pp. - \$1.50]

002 M.W. Frankena, "Alternative Models of Rent Control" (September 1975).

003 J.R. Markusen and D.T. Scheffman, "Ownership Concentration and Market Power in Urban Land Markets" (October 1975).

004 A.J. Robson, "The Effect of Urban Structure on Ambient Pollution" (October 1975).

005 J.R. Markusen and D.T. Scheffman, "The Timing of Residential Land Development: A General Equilibrium Approach" (November 1975).

006 A.J. Robson, "Cost-Benefit Analys is and the Use of Urban Land for Transportation" (December 1975).

007 M.F. Goodchild and P.J. Booth, "Modelling Human Spatial Behavior in Urban Recreation Facility Site Location" (January 1976).

008 M.W. Johnson, "Consumer Location and Local Public Goods" (March 1976).

009 K.L. Avio and C.S. Clark, "The Supply of Property Offenses in Ontario" (April 1976). 
010 P.T. Chinloy, "Depreciation, Adverse Selection and Housing Markets" (May 1976).

011 C.L. Poon, "An Economic Evaluation of Urban Railway Relocation" (September 1976).

012 A.J. Robson, "Income Uncertainty and Urban Location" (September 1976).

013 M.W. Frankena, "An Error in Estimating Urban Density Functions Using Census Tract Data" (October 1976).

014 G.W. Davies, "The Demand for Automobiles in Canada" (December 1976).

015 M.W. Frankena, "The Demand for Urban Bus Transit in Canada" (December 1976).

016 A.J. Robson and D.T. Scheffman, "The Crunch, the Boom, and the Recreational Land Market" (January 1977).

017 A.G. Blomqvist and W. Haessel, "Smal1 Cars, Large Cars, and the Price of Gasoline" (January 1977).

RESEARCH STUDIES:

01 G.W. Davies and P.L. Jackson, "A Model of the Urban Housing and Residential Land Markets" (September 1975).

02 G.P. Schaefer, "The Urban Area Production Function and the Urban Hierarchy: The Case of Saskatchewan" (October 1975).

03 C.L. Poon, "A Cost-Benefit Study of Urban Railway Relocation" (November 1976).

*This report is out-of-print. Xerox copies can be obtained for a minimal charge of $5 \$$ per page. 